\title{
Problem-Based Learning in Engineering Education: Reflections, Practices, and Challenges
}

\author{
Waddah Akili, Ph.D., P.E. \\ Professor of Civil Engineering (Retired) \\ Principal, Geotechnical Engineering, Ames, IA, Email:w.akili@isunet.net
}

\begin{abstract}
This paper focuses on the utilization of problem-based learning (PBL) in an engineering program, and argues that implementation of problem-based learning needs to be placed in a context and must be developed with careful consideration of the social, economic, and ethnic diversity of the student population and the university academic culture and prevailing norms. The paper includes a brief history, selected PBL models, strategies to infuse PBL in an engineering program, and suggestions for redesigning classes and courses to catalyze change in the classroom environment through student engagement. The paper, also, addresses the potential difficulties that could arise during implementation of PBL, and argues for the need to conduct research in order to guide the process of transition from the old to the new paradigm.
\end{abstract}

\section{Introduction}

Achieving change via engineering education reform is a formidable challenge to any college of engineering, whether in North America or anywhere else in the world. In the past two decades, engineering educators have tried to implement relatively new methodologies in the classroom, primarily characterized by students' active engagement or involvement in his or her academic work, resulting in better retention of new knowledge and acquisition of desirable personal traits. Any such method that engages students in the learning process is labeled as: "active learning" method. In essence, active learning requires doing meaningful learning activities in groups under the guidance of an informed and experienced teacher. As stated by Christensen et al (1991), "To teach is to engage students in learning." The main point is that engaging students in learning is principally the responsibility of the teacher, who becomes less an imparter of knowledge and more a designer and a facilitator of learning experiences and opportunities. In other words, the real challenge in college teaching today is not covering the material for the students, but rather uncovering the material with the students (Smith et al 2005).

There are several strands of pedagogies of engagement under the umbrella of active learning methods that have received attention by engineering educators world-wide (Smith et al 2005; Prince 2004). These methods/approaches are known to increase students' active engagement in learning and also, promote cognitive elaboration, enhance critical thinking, and contribute toward social and emotional development. The most utilized pedagogies in engineering 
education today, and moving in the same broad direction, are: problem-based learning, cooperative learning, and collaborative learning (Smith et al 2005).

Problem-based learning (PBL) starts when students are confronted with an open-ended, illstructured, real-world problem and work in teams to identify learning needs and develop a viable solution, with instructors acting as facilitators rather than primary sources of information (Prince 2004). There are numerous PBL teaching models, and are all equally valid and appear to work depending on factors and prevailing circumstances such as: 1) characteristics of the curriculum, 2) attitudes, knowledge, and skills of the academic staff, 3) underpinning academic culture of teaching and learning, and, 4) socio-economic background and abilities of the student body (Smith et al 2005; Prince 2004; Prince and Felder 2006). The paper examines different variations of PBL, selects suitable versions for potential adoption at the start, identifies essential elements of a well-structured learning strategy, and illustrates faculty role in implementing PBL.

Proven methodologies and knowledge generated elsewhere, if and when properly adapted, should make it possible for institutions to devise their own PBL models that meet their classroom setting, objectives, and aspirations. The paper sheds light on the nature of such models and argues for the need to conduct research in order to guide the process of transition from the old to the new paradigm, to ensure the vitality and currency of engineering education.

\section{Active Learning: Definitions and Interpretations}

It is difficult to come to grip with all the cited definitions, meanings, and interpretations of the term "active learning", since different contributors in the field have interpreted some terms differently. However, by gleaming at the literature, it is possible to arrive at general consensus of what appears to be widely accepted definitions, and shed light on how common terms are used. Active learning is generally defined as any instructional method that engages students in the learning process. It is widely accepted that active learning requires students to take part in "preplanned" learning-related activities, believed to spark and stimulate their learning, while in the classroom(Bloom 1956; Randolph 2000) .These activities would include: reading, writing, solving problems, answering questions, participating in a discussion, etc.; and most important, students must be engaged in thinking tasks while actively involved. It is generally understood that during active learning, less emphasis is placed on transmission of information and more on developing students' skills. Additionally, during an active learning cycle, emphasis is placed on students' exploration of their own abilities, including: their thinking process, their value system, their intellect, and their courage to express themselves orally and in writing. Active learning is contrasted to the traditional lecture where students passively receive information from the instructor (Bloom 1956; Kolb 1984; Frederick 1987).

Collaborative learning refers to any and all of the instructional methods where students work together in small groups towards a common goal (Smith et al 2005; Prince 2004). It can be viewed as encompassing all group-based instructional methods, including cooperative learning (Frederick 1987; Millis and Cottell 1998). The central element of collaborative learning is collaboration vs. individual work (Prince 2004). Meta-analysis supports the view that collaboration does promote a broad range of learning outcomes. In particular, collaboration enhances academic achievement, and student attitudes. It also reduces attrition (Prince 2004). Cooperative learning is a formalized active learning structure where students work together in small groups to accomplish shared learning goals and to maximize their own and each others 
learning. The most common model of cooperative learning in engineering is that of Johnson, Johnson and Smith (1991).This model has five specific elements: mutual interdependence, individual accountability, face to face interaction, interpersonal and small group skills, and individual assessment of group functioning (Johnson et al 1991). Although different cooperative models exist (Springer et al 1999), the core element in all, is the emphasis on cooperative incentives rather than competition in the promotion of learning. Some researchers view cooperative and collaborative learning as having two distinct historical developments and differing philosophical roots (Wales and Stager 1978). Despite differences and similarity of the two approaches (collaborative vs. cooperative), the fact is: that the core element of both is the emphasis on interactions, as the primary source of learning, rather than learning as individuals.

Problem-based learning (PBL) is an instructional method where relevant problems are introduced during the course to provide the context and motivation for the learning that follows (Mourtos 1997). PBL, by and large, is self-directed learning that helps develop positive student attitudes, foster a deeper approach to learning, and helps students retain knowledge longer than traditional instruction. It is appropriate here to mention that several approaches go under the name of problem-based-learning. These approaches to PBL have as many differences as they have elements in common, making interpretation of outcome rather difficult (Mayo et al 1993).

Before adopting a specific method of active learning, faculty members need to become familiar with the literature, and, in particular, the various strategies that promote active learning in the classroom. Despite familiarity with the literature, ambiguity and confusion may result, at times, from reading the literature; particularly when the effectiveness of any instructional method is compared with another method. Assessing "what works" requires looking at a broad range of learning outcomes, interpreting results carefully, and quantifying the magnitude of any reported improvement. To assess "what works" for a given set of conditions, the reader has to attain sufficient knowledge and familiarity with the subject matter (Prince 2004; Smith et al 2005).

Reported studies, by and large, tell us about success stories and seldom reveal what has not worked. Irrespective of how data, results, and interpretations are presented in the literature, faculty adopting a specific method with the expectations of experiencing similar results to those in the literature, should be aware of the limitations of any reported piece of research, i.e., such reports may not reveal all factors and details; and therefore, extrapolating without a thorough investigation could be misleading. This should not, by any means, discourage faculty from moving toward active learning; but rather intended as a "precautionary" observation, to new instructors: Not "to make too much" out of what they have read unless it is credible, thorough, and substantiated with facts and figures. Despite some pitfalls, engineering faculty should be strongly encouraged to examine the literature on active learning, including: the empirical research on its use, and the common barriers that may arise as a consequence of its application.

The author believes that learning "about" things is not enough to enable students to acquire the skills they will need in the future. Rather pedagogies of engagement, such as PBL, when properly implemented, will turn out the kinds of resourceful, engaged professionals that engineering practice needs. In the sections that follow, the author presents: i) relevant information on PBL, its practices and working models; ii) cooperative learning as a priori to PBL ; and, iii) the lecture format, if and when combined with a selected active learning strategy, such as PBL- and its potential utilization in a traditional classroom setting. 


\section{Problem-Based Learning: Historical Origin, Precepts, Practices, and Working Models}

The modern history of PBL begins in the 1970s at the medical school at McMaster University in Canada. Until recently, the PBL approach has flourished mainly in medical and professional schools. Slowly the sciences, have begun taking it up. PBL does not have a store of transferable techniques like cooperative learning, no "jigsaw," no "think-pair-share" or that sort of thing. Opinions vary on whether PBL should be implemented for entire courses or merely in parts of courses. Generally, advocates accept easing into it piecemeal, but favor course-long continuity.

In some ways what PBL is, seems self-evident: It's learning that results from working with problems. Official descriptions generally describe it as: an instructional strategy in which students confront contextualized, ill-structured problems and strive to find meaningful solutions. In other words, in PBL, learning results from the process of working toward the understanding or resolution of a problem. The problem is encountered first in the process (Barrows and Tamblyn 1980). Barrows (1996) identifies six core features of PBL: i) Learning is student-centered. ii) Learning is best accomplished in small groups. iii) Problems are the main focus for learning. iv) Problems are the vehicle for the acquisition of problem-solving skills. v) Teachers are facilitators of learning. And, VI) New information is acquired through self-directed learning.

The list of reasons for the deployment of PBL includes the fact that problem-based learning (PBL) ends up orienting students toward meaning-making over fact-collecting. Students learn via contextualized problem sets and situations. Because of that, and all that goes with it, namely the dynamics of group work and independent investigation, they achieve higher levels of comprehension, develop more learning and knowledge-forming skills and more social skills as well. This approach to teaching brings prior knowledge into play more rapidly and ends up fostering learning that adapts to new situations and related domains quickly and effectively. According to Woods (1994), PBL is suitable for introductory sciences and engineering classes as it is for medicine- because it helps students develop skills and confidence for formulating problems they have never seen before. But where does PBL fit compared with all the other "learning methods". Faculty hear about--"cooperative learning," "collaborative learning," and "active learning"? The proliferation of "learnings" and their attendant partisan camps invites the reawakening of long-standing faculty prejudice against educational fads and "methods." Even so, interest in PBL grows because not only does research show a higher quality of learning (though not a greater amount if "amount" equates with the number of facts), but problem-based learning simply feels right intuitively. It seems to reflect the way the mind actually works, not a set of parlor-game procedures for manipulating students into learning .Unfortunately, while there is agreement on the general definition of PBL, implementation has varied widely(Prince 2004)..The large variation in PBL practices makes the analysis of its effectiveness a bit complex. Many studies comparing PBL to traditional programs are simply not talking about the same thing. As reported by Prince (2004), "For meta-studies of PBL to show any significant effect compared to traditional programs, the signal from the common elements of PBL would have to be greater than the noise produced by differences in the implementation of both PBL and traditional curricula." Despite this, there are positive findings that do emerge from the literature, which support the following: i) PBL produces positive student attitudes, ii) provides more motivating and enjoyable approach to education, iii) improves long-term retention of knowledge compared to traditional instruction, and iv) promotes deep learning and problem-solving skills( Prince 2004). 
A. Essentials of PBL: Problem-based learning is a philosophy that has to be adapted to the specific conditions and situation of an institution, and the nature of the specific field in which it is to be implemented. This is apparent in the different models of PBL implementation through out the world. Therefore, there is no one-size-fits-all approach to PBL that can simply be implemented from one institution to another (Allen et al 1996). There are required steps that have to be mobilized at the start of PBL. At the start of learning in PBL is the selection of real problem(s). This is, in fact, the major driving force for learning. Effort and time dedicated to the selection of problem(s) is time well-spent and will eventually pay off. The problem(s) should be well crafted to engage and immerse students in learning new materials, as well as challenging existing knowledge, skills, and attitude. It is important to note that PBL is not only about giving problems and solving them in classroom, but it is also about creating opportunities for students to construct knowledge through interactions and collaborative inquiry (Allen et al 1996).

In PBL, the instructor is primarily a facilitator, whose role is to make the learning process visible, instead of making the content visible as in traditional lectures. Since assessment drives learning, the modes of assessment must also be modified to appropriately evaluate students for the desired outcomes that have been designed for the problem. For students to become problem solvers, they have to be actively involved in the learning process. When students are exposed to PBL for the first time, they must be guided, prepared, and motivated. It is not fair to expect students to readily have the skills for PBL, particularly when they have been exposed solely to traditional classroom environment. Therefore, students need to be prepared by exposing them to informal cooperative learning, where students are to work together to achieve a joint learning goal in temporary, ad-hoc groups that may last from a few minutes to one class period (Johnson et al 1998). Informal cooperative learning groups also ensure that misconceptions and gaps in understanding are identified and corrected. Using procedures such as informal cooperative learning guarantees their exposure to active and interactive methods prior to engaging in PBL.

B. Infusing PBL in the Curriculum: There are several strategies that may be utilized to infuse PBL in an engineering curriculum. The selected strategy depends upon: 1) the commitment of the institution, as a whole, to the process of deploying active learning schemes in general, and PBL in particular, 2) the readiness of the teaching staff, and 3) available recourses, facilities, and support services. Table 1 illustrates three approaches to infuse PBL in the curriculum as suggested by Tan (2003): at the mega, macro and micro levels. Implementing PBL at the mega level requires commitment from the administration as well as from the teaching staff. As shown in Table1, an example of such an implementation is when students acquire their course work in its entirety, during the third or fourth year, by means of PBL. This would require a major revamp of the curriculum, along with realignment of program's objectives and outcomes. At the macro level, certain courses in the curriculum are designated to be taught utilizing PBL, irrespective of who is in charge of the course. A macro implementation requires departmental approval and a firm commitment by the instructors teaching the course. Courses offered in multiple sections require coordination between instructors. The micro-level approach requires the least amount of resources. Its implementation is flexible, non-binding and amendable. This is where PBL can be used on a trial basis for certain topics in a selected course(s) within a certain time limit. Hence, this approach is highly recommended for trying out PBL for the first time.

C. The Start up of PBL: A gradual, step at a time approach, should be taken when infusing PBL in a program. At the start, steps should be taken to raise awareness and educate instructors 
and students on key issues, techniques and potential hurdles that may arise when using PBL for the first time. During this initial period, it is advisable to form a central committee from experienced or semi-experienced lecturers, who are at ease with active learning strategies in general and PBL in particular, to facilitate the promotion of PBL at all levels of the academic community. This is a challenging time that requires patience, persistence, and social skills on the part of the committee members entrusted with the task of embarking on the process- where the committee will be moving against the tide in trying to plant the seeds of change. The major tasks that would be undertaken at this stage are: introduce PBL gradually and properly, convince teachers and students of its merits, and help train potential lecturers of when and how to use PBL. As instructors gain familiarity with PBL, they begin to develop their own techniques.

\begin{tabular}{|l|l|ll|}
\hline \multicolumn{1}{|c|}{ Level } & \multicolumn{1}{|c|}{ Range of Application } & \multicolumn{1}{c|}{ Details } \\
\hline Mega Level & $\begin{array}{l}\text { PBL is applied to the entire 3rd or 4th } \\
\text { year of a selected program }\end{array}$ & $\begin{array}{l}\text { Major revamp of curriculum } \\
\text { - }\end{array}$ \\
\hline $\begin{array}{l}\text { Macro } \\
\text { Level }\end{array}$ & $\begin{array}{l}\text { PBL applied to two or three subjects } \\
\text { in the 3rd or 4th year of a selected } \\
\text { program }\end{array}$ & $\begin{array}{l}\text { Need departmental approval and } \\
\text { firm commitment from the } \\
\text { lecturers teaching the selected } \\
\text { subjects }\end{array}$ \\
\hline $\begin{array}{l}\text { Micro } \\
\text { Level }\end{array}$ & $\begin{array}{l}\text { PBL is applied to specific topics in a } \\
\text { selected one or two courses }\end{array}$ & $\begin{array}{l}\text { Recommended for new starters } \\
\text { Will require proper coordination } \\
\text { when implemented in courses } \\
\text { with multi sections }\end{array}$ \\
\hline
\end{tabular}

Table 1. Different approaches of infusing PBL

\section{Student Engagement Using Cooperative Learning Structures: A Priori to PBL}

As noted earlier, relying solely on the traditional lecture approach, no matter how competent the lecturer is, fails to engage students in learning; thus indirectly depriving students of learning experiences and opportunities that could only materialize utilizing engagement strategies. Under the umbrella of engagement strategies, there are numerous models available to select from, including the models predicated on cooperation - working together to accomplish shared goals. Within cooperative strategies, individuals seek outcomes that are beneficial to themselves and beneficial to all group members within the class (Johnson et al 1991; Smith et al 2005). The work by Johnson et al (1991) reveals that students exhibit a higher level of individual achievement, develop more positive interpersonal relationships, and achieve greater levels of academic self-esteem when participating in a successful cooperative learning environment.

Cooperative learning researchers and practitioners have shown that positive peer relations are essential to success in college. The positive interpersonal relationships, promoted through cooperative learning, are regarded by most as crucial to today's learning communities. The underlying precept of cooperative and problem-based learning is "interdependence".

Cooperation is more than being physically near other students. It is the will to open up to others, exchange information and views with others, and accept the fact that working together is more beneficial to all involved in the exercise. For a cooperative learning to be successful, it is imperative that the following be integrated into the class activity (Lowman 1984; McLeod 1996): 
- Positive Interdependence-Students should perceive the need for one another to perform the planned activity.

- Face to Face Interaction- Students should work together in planning, executing, and arriving at conclusions. They should share the work load, and share the credit.

- Accountability-Each student's role and performance is to be assessed, and the results are those of the group (and for the group). Keeping track of the contribution and knowledge gained by each member could be monitored, as well, by either testing every student in the group, or by randomly selecting a group member to be tested and thus proxy for the group.

- Sharing known skills- Students who possess certain skills (examples: computer skills, laboratory skills, data reduction skills, presentation skills) should be willing to pass it on, and/or share it with their group members.

- Collaborative Skills- Groups cannot function effectively if members do not have (be willing to learn) or use some needed social skills. These skills include leadership, decision making, trust building, and conflict management.

- Monitoring Progress- Groups need to discuss amongst each other whether they are achieving set goals; they also need to prioritize the scheduled activities, solicit advice and assistance with the consent of the instructor, and maintain working relationships among the members.

Success in implementing problem-based cooperative learning is attributable, in large measure, to: proper planning, efforts, dedication, and foresight of the instructor. Experience definitely is a major factor. A proper start for instructors wanting to try any of the active learning strategies for the first time (including problem-based cooperative learning) is to step into it gradually, and to seek feedback as to how the course is going and how the students feel about it. Also, he/she can tap into documented sources, and discuss planned activities with experienced colleagues.

\section{The Lecture Format together with Active Learning Strategies}

When asked why he lectures, one faculty responded: "It is tradition. It was part of my training, and seems to dwell in me and seems like what I should be doing. I feel guilty when I am not lecturing" (Creed 1986). This candid statement suggests one of the great dilemmas faced by all who teach at the post-secondary level. Lecturing is virtually synonymous with teaching. It was the dominant method by which we were taught - and it is the method by which most of us teach. When discussing potential change in current teaching-learning strategies, many faculty members become defensive, and discussions may quickly degenerate into heated debates where sides are clearly drawn. Over-exuberant advocates of active learning have, unfortunately, not been able to persuade the majority of those who have grown accustomed to traditional teaching methods. More efforts and better approaches in persuading the traditionalists appear necessary. The challenge is to choose a suitable method at the appropriate time. Understanding the pros and cons of the lecture method is a helpful start.

Lectures have a number of characteristics that does make them, for the right subject matter, desirable in the classroom (Creed 1986). It does, to a great extent, depend on the abilities and experience of the lecturer. An able and committed lecturer can accomplish the following:

1. Relate the material proficiently and effectively, in a manner that reflects lecturer's personal conviction and grasp of the subject matter;

2. Provide students with a thoughtful, scholarly role model to emulate; 
3. Supplement the subject matter with current developments not yet published, or interject lecturer's own views derived from his/her own experience whenever applicable;

4. Organize material in ways to meet the particular needs of a given audience;

5. Efficiently deliver large amounts of information when the need arises without confusion;

6. Underscore key points, simplify complexities, illustrate with facts and figures.

In addition, lectures are presumably cost-effective in that they can reach many listeners at one time, they present a minimum threat to students in that they are not required to actively participate, and they provide an advantage for those students who find learning by listening enjoyable (Creed 1986). As most students will attest, not all lectures or lecturers achieve these goals. Research findings suggest that a number of identifiable attributes must be implemented to make a lecture truly effective. For instance, students remember material presented at the beginning of a lecture better than information presented in the middle or at the end of the lecture. Also, the effectiveness of the lecture varies inversely with the difficulty of the material presented, and listeners retain factual material better when presented in short sentences rather than in long sentences. These characteristics presume that the lecturer is an enthusiastic and knowledgeable scholar. But, we realize that most campuses have a few that fit this description, and could keep most students interested during the formal 50-minute lecture. Even if it is assumed that most engineering lecturers possess these necessary characteristics, research has shown that the exclusive use of the lecture in the classroom constrains students' learning.

An important problems associated with total reliance on the lecture method is the inability of most students to listen effectively to any lecturer, no matter how skillful, over a sustained period. Ten to 20 minutes into the lecture, however, confusion and boredom set in and assimilation fell rapidly, remaining at a low state until a brief period toward the end of the session when students were revived by the knowledge that the lecture would soon be over (Penner 1984). There are too many reports in the literature on lack of concentration by the audience, even when the lecturer is brilliant and the attendees are highly motivated, including medical students (Bonwell 1991). When it comes to "note-taking" during a 50 minute lecture, research has shown that students have noted 40 percent of the content presented during the first 15 minutes, 25 percent of the total content in a 30 minute-period, and only 20 percent during 45 minutes (Penner 1984). Even with competent students listening to an interesting topic, several problems remain, including:

1. Course content is often presented via lecture in unorganized and uneven fashion. This makes it difficult for students to determine the most important aspects of the lecture;

2. Many college students do not know how to take effective notes. Although formats for effective "note-taking" have been identified. The fact is: that "note-taking" is seldom taught;

3. The listening, language, and motor skill deficits of students make it difficult to identify important lecture content and write it correctly and quickly enough during a lecture;

4. Instructors sometimes get off-track from the primary objectives of the lecture. Professorsespecially those who really know and love their disciplines - are famous for going off on tangents. Although getting off-track breaks the monotony, it could make it difficult for even the most skilled note-takers to determine the most important content.

For those instructors who would like to go beyond the traditional methods of lecturing, a number of effective strategies promoting active learning are available to choose from. If a faculty member is hesitant about selecting one or more of these active learning strategies because some questions exist about its comparative effectiveness with the lecture method, he or she should 
consider the following: research has shown, beyond the shadow of doubt, that these strategies do deliver content as well as lectures while providing diverse presentations that enhances students' motivation and achievement, and helps in building up desirable personal traits.

\section{Concluding Remarks}

On the whole, the intended move towards encouraging instructors to adopt problem-based learning (PBL) seems farfetched and difficult to accomplish, especially in the initial stage. This is because time is needed for those undertaking the task to be trained to implement and gain the experience necessary to move the process forward. Time is also needed for other stakeholders to be convinced and to provide the support needed to prescribe the change. Most importantly, those promoting the change must be able to show that PBL is effective for engineering education.

It is highly recommended that an Active Learning Taskforce be formed of experienced faculty, to initiate, infuse, and oversee the progress made. Their determination, patience, and resilience are required to successfully promote college-wide implementation of PBL. Nevertheless, with clear intentions, goals and plans of action, coupled with support from the highest level of the University's key personnel, the Taskforce and other core groups, should be able to move the process forward. Success would almost be guaranteed, when a well-coordinated university-wide implementation of PBL is underway in other colleges of the University.

\section{Bibliography}

1. Allen, D. E., Duch, B. J., and Groh, S. E., "The Power of PBL in Teaching Introductory Science Courses," in Wilkerson, L. and W.H. Gijselaers, eds., New Directions for Teaching and Learning, No. 68, pp.3-11, San Francisco, Cal., Jossey-Bass Publishers, 1996.

2. Barrows, H. S., "Problem-Based Learning in Medicine and Beyond: An Overview," in Wilkerson, L. and W.H. Gijselaers, eds., New Directions for Teaching and Learning, no. 68, pp.3-11, San Francisco, Cal.: Jossey-Bass Publishers, 1996.

3. Barrows, H.S., and Tamblyn, R. N. Problem-Based Learning: An Approach to Medical Education, New York, N.Y., Springer, 1980.

4. Bloom, B.S., Taxonomy of Educational Objectives: The Classification of Educational Goals by a Committee of College and University Examiners, McKay Co., Inc., New York, NY, 1956, pp.189-193.

5. Bonwell, C.C., and J.A. Eison, "Active Learning: Creating Excitement in the Classroom," ASHE-ERIC Higher Education Report No.1, George Washington Univ, Wash., DC, 1991

6. Christensen, C.R., Garvin, D.A., and Sweet, A., "Education for Judgment: The Artistry of Discussion Leadership", Cambridge, Mass.: Harvard Business School, 1991.

7. Creed, Thomas, "Why We Lecture," Symposium: A Saint John's Faculty Journal, no.5: 1986: pp. 17-23.

8. Frederick, Peter J., "Student Involvement: Active Learning in Large Classes," In Teaching Large Classes Well, edited by M.G.Weimer. New Directions for Teaching \& Learning no.32, Jossey-Bass, San Francisco, Ca, 1987. 
9. Johnson, D.W., Johnson, R.T., and Smith, K.A., Cooperative Learning: Increasing College Faculty Instructional Productivity, ASHE-ERIC Report on Higher Education, Washington, D.C.: The George Washington Univ., 1991.

10. Johnson, D.W., Johnson, R.T., and Smith, K.A., Active Learning: Cooperation in the College Classroom, 2nd ed., Edina, MN: Interaction Book Company, 1998.

11. Kolb, D.A., "Experiential Learning: Experience as the Source of Learning and Development," Prentice Hall, Englewood Cliffs, CA, 1984.

12. Lowman, J., Mastering the Technique of Teaching, Jossey-Bass, San Francisco, CA. 1984.

13. Mayo, P., M.B.Donnelly, P.P.Nash, \& Schwartz, R. W., "Student Perceptions of Tutor Effectiveness in Problem Based Surgery Clerkship," Teaching and Learning in Medicine vol.5, no.4, 1993, pp. 227-233.

14. McLeod, A., "Discovery and Facilitating Deep Learning States," National Teaching and Learning Forum, Vol.5, no.6, 1996, pp.1-7.

15. Millis, B., and Cottell Jr. P., "Cooperative Learning for Higher Education Faculty," American Council on Education, ORYX Press, 1998

16. Mourtos, N.J., "The Nuts and Bolts of Cooperative learning in Engineering," Journal of Engineering Education, vol. 86, no.1, 1997, pp.35-37.

17. Penner, Jon, G., Why Many College Teachers Cannot Lecture. Charles C. Thomas, Springfield, Ill., 1984.

18. Prince, M., "Does Active Learning Work? A Review of the Research," ASEE Journal of Engineering Education, vol. 93, no.3, 2004, pp.223-231.

19. Prince, M., and Felder, R.M., "Inductive Teaching and Learning Methods: Definitions, Comparisons \&Research Bases," ASEE J. of Eng. Education, vol.95, no.2, 2006, pp.123-138.

20. Randolph, G.B., "Collaborative Learning in the Classroom: Writing Across the Curriculum Approach.” Journal of Engineering Education, vol.89, no.2, April 2000, pp.119-122.

21. Smith, K.A., Sheppard, S.D., Johnson, D.W., \& Johnson, R.T., "Pedagogies of Engagement: Classroom-Based Practices," ASEE J. of Eng. Education, vol. 94, no.1, 2005, pp.87 -102.

22. Springer, L., M. Stanne, and S. Donavan, "Effects of Small-Group Learning on Undergraduates in Science, Mathematics, Engineering, and Technology: A Meta-Analysis," Review of Educational Research, vol.69, no.1, 1999, pp.21-52.

23. Tan, O.S., Problem-Based Learning Innovation: Using Problems to Power Learning in the 21st Century. Singapore: Thomson Learning, 2003.

24. Wales, Charles E., and Robert A. Stager, The Guided Design Approach, Educational Technology Publications, Englewood Cliffs, N.J., 1978.

25. Woods, D.R., Problem -Based Learning: How to Gain the Most from PBL, Waterdown, Ontario: Donald R. Woods, 1994.

WADDAH AKILI: Professor (retired) of civil engineering \& visiting faculty at Iowa State Univ., Ames, IA. Has been in the academic arena for over 38 years. He has held academic positions at Drexel University, Philadelphia, Penna (66-70); at King Fahd University of Petroleum \& Minerals, Dhahran, Saudi Arabia (70-87); \& at The University of Qatar, Doha, Qatar (87-00). Akili's major field is geotechnical engineering. His research interests and experience includes: characterization of arid and semi arid soils, shallow and deep foundations, pavement design and materials, concrete durability, and contemporary issues of engineering education, in general, and those of the Middle East in particular. He is presently a geotechnical consultant in Ames, Iowa. 